\title{
FROM CANTOR TO CHRISTALLER?
}

\author{
E SCOTT MORRIS \\ University of Texas, Dallas \\ Manuscript received: June 26, 2014 \\ Revised version: October 6, 2015
}

MorRis E.S., 2015. From Cantor to Christaller? Quaestiones Geographicae 34(4), Bogucki Wydawnictwo Naukowe, Poznań, pp. 83-84, 1 fig. DOI 10.1515/quageo-2015-0039, ISSN 0137-477X.

Aвstract: It is possible that Georg Cantor and Walter Christaller may have been aware of one another during their careers, however, there is no indication the two collaborated. Also, there is no documentation that Christaller's central place theory (CPT) contains any tenets derived from Cantor's middle third set (CMT). Regardless, CMT and CPT are linked by their constructions as nested hierarchies and the geometry of hexagons. The end points and intervals of CMT may be incorporated, respectively, as anchor points and radii for the hexagonal tessellations of central place theory.

KEY WORDS: fractal, urban model, Cantor set, central place theory

E Scott Morris, 1514 Broadway St., Denton TX, 76201, USA; e-mail: misteremorris@gmail.com

\section{Cantor's middle third set}

Cantor's set is one that is based on an underlying rectilinear geometry. Consider its construction as follows. Take a line segment, divide it into thirds, and remove the middle third. Continue this process on the remaining two segments. Repeat the process endlessly. The result is the Cantor middle third set (CMT), which consists of limits of end points of intervals (Cantor 1915). Figure 1 suggests the process through four iterations. To visualize the endless process, think of the set becoming dust.

\section{Binary representation of Cantor's middle third set - the fractal connection}

In fractal geometry, an initiator is the starting shape to be modified through successive iterations (Mandelbrot 1983). For the CMT, the initiator is the closed interval $[0,1]$ at the outset (level $s$ $=0$ of the iterative process). At each subsequent iterative level, a generator is applied to the current geometric object(s). For example, if $(1 / 3,2 / 3)$ is removed from $[0,1]$, then the values remaining in

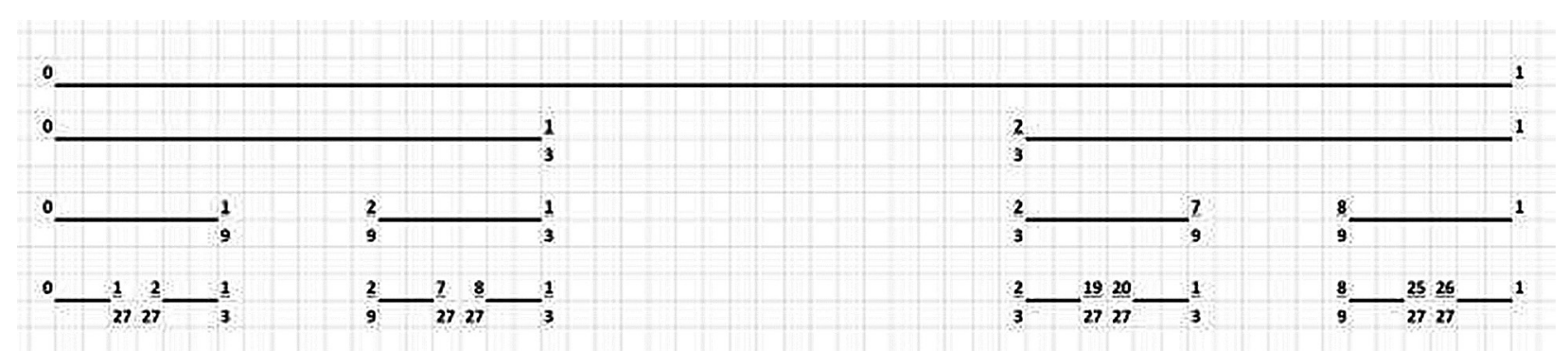

Fig. 1. Cantor's middle third set through four iterations 
the CMT at level $s=1$ are $[0,1 / 3] \mathrm{U}[2 / 3,1]$. Once a point is an endpoint of an interval, it remains in the set. As the process continues, the resulting set is a fractal dust, formed from the collection of points never removed.

It is a straightforward matter to create a binary representation of the Cantor interval (I) and the respective hierarchical level. For example, $I(0)=[0,1 / 3]$. Generally,

$$
\begin{gathered}
I(\Omega)=[0,1] \\
I\left(\Omega_{s}\right)=I\left(\omega_{s, i}\right) \ldots I\left(\omega_{s, i}\right)=\left[a_{s, i^{\prime}} b_{s, i}\right] \ldots\left[a_{s, i^{\prime}} b_{s, i}\right]
\end{gathered}
$$

such that $a_{s, i}=$ the left endpoint $\}$ and $b_{s, i}=\{$ the right endpoint $\}$ for interval (i) of hierarchical level $s$. Also, $s=\{$ the number of 0 's or 1's in $(\omega)\}$ and $i \in\left[1,2^{\mathrm{i}}\right]$. The binary coding - where $\omega=I_{1} \ldots I_{n}$ is a unique series of 0 's and $1^{\prime}$ s and each $I_{n}=\{0$ or $1\}$ - simplifies the notation with the realization that a 0 represents the left third of the interval $s-1$, and 1 represents the right interval from $s-1$. For example, at $s=3$,

$$
I(00)=\left[0, \frac{1}{9}\right] \text { and } I(01)=\left[\frac{2}{9}, \frac{1}{3}\right]
$$

In $I(00)$, the first 0 implies the left segment was chosen at $s=1$, and the second 0 means the left interval was chosen at $s=2$, while $(1 / 9,2 / 9)$ is not in $\Omega_{3}$. In contrast, $I(01)$ denotes that the left segment was chosen at $s=1$ and the right segment chosen at $s=2$. Likewise, both $I(10)$ and I(11) indicate that the right segment was selected at $s=1$. Figure 1 illustrates the binary representation procedure through three hierarchical levels of the CMT.

\section{The fractal connection as a pivot to other theories}

Because the CMT can be captured as a nested hierarchy using fractal iteration sequences to generate it, a natural place to look for further connection is to central place theory (Christaller 1933) and its characterization using fractal generation sequences. In 1985, Arlinghaus illustrated how to do this process for all $K$ values, and in 1989 Arlinghaus and Arlinghaus proved how to do it for all possible $K$ values and for all outstanding previously posed unsolved problems derived from a non-fractal approach (Dacey 1965). What is sought in the future is to attempt to capture similar power from a fractal characterization of the CMT and eventually to consider its implications in urban planning, which is often based on an underlying rectilinear geometry rather than on a hexagonal one.

\section{References}

Arlinghaus S.L., 1985. Fractals take a central place. Geografiska Annaler, Series B, Human Geography 67(2): 83-88. Stable URL: http://www.jstor.org/stable/490419. Persistent URL (URI): http:/ / hdl.handle.net/2027.42/58740

Arlinghaus S.L., Arlinghaus W.C., 1989. The fractal theory of central place hierarchies: a Diophantine analysis of fractal generators for arbitrary Löschian numbers. Geographical Analysis 21(2): 103-121. Ohio State University Press. Persistent URL (URI): http:/ / hdl.handle.net/2027.42/59708

Batty M., Longley P., 1994. Fractal cities: A geometry of form and function. Academic Press, New York.

Cantor G. [1915] in Jourdain P. (ed.), 1955. Contributions to the founding of the theory of transfinite numbers. Dover, New York.

Christaller W., 1933. Die zentralen Orte in Süddeutschland. Gustav Fischer, Jena.

Dacey M.F., 1965. The geometry of central place theory. Geografiska Annaler, B, 47: 111-124.

Mandelbrot B., 1983. The fractal geometry of nature. W. H. Freeman, San Francisco. 